\title{
The Concept of Triple Helix Mohammad Natsir and its Implementation in Strengthening Religious Character Education
}

\author{
Rizal Firdaus ${ }^{1}$, Kama Abdul Hakam², Momod Abdul Somad², Ahmad Syamsu Rizal ${ }^{2}$ \\ ${ }^{1}$ STIBA Ar-Raayah, Graduate Student of Indonesia University of Education \\ 3 Indonesia University of Education \\ rizalfirdaus9@gmail.com
}

Article History:

Received: June $12^{\text {th, }} 2020$

Revised: August $13^{\text {th }}, 2020$

Accepted: September 30th, 2020

\begin{abstract}
Abstrak
This article aims to discuss the concept of triple helix Mohammad Natsir which he often refers to as the three pillars of Muslims' power and associate it with the idea Kampus Merdeka and Merdeka belajar to strengthen the education of religious characters at the university level. A method that uses a qualitative approach with data sourced library data. This article's result is the concept of triple helix mohamad Natsir namely the integration of education between three institutions, masjid, pesantren and campuses. Among the cooperation programs that can be done are internship programs, making humanitarian projects, teaching, and researching potential mosques or pesantren. In order for this program to run according to the plan in advance must agree on the concepts and purpose of education, agree to the integration and conversion of the curriculum, and monitoring and evaluation periodically.
\end{abstract}

Keywords: Mohammad Natsir, Triple Helix Concept, Religious Character

$$
\begin{aligned}
& \text { مقدمة } \\
& \text { التعليم الثخصي هو الغرض الرئيسي للتعليم في إندونيسيا، كما هو الحال في دستور جهورية } \\
& \text { إندونيسيا في عاه } 1945 \text { فصل } 31 \text { أية (c)، بمعنى أن أساس التربية الوطنية هو الإيمان والتقوى } \\
& \text { والأخلاق النبيلة (Firdaus et al., 2020; Husaini, 2020). وقد حظي القانون بدعم من قانون نظاه } \\
& \text { التعليم الوطني في عام } 2003 \text { ، وتم تعزيزه باللائحة الرئسية لجمهورية إندونيسيا في عام } 2017 \text { بثأن تعزيز } \\
& \text { تعليم الثخصيات (PPK). في التعزيز يذكر أن القيم الخمس الرئيسية للتعليم الثخصية في اندونيسيا } \\
& \text { هي الطابع الديني (karakter religius) ، والنزاهة الثخصية (karakter integritas) ، غوتونغ رويونغ }
\end{aligned}
$$


الطابع (karakter gotong royong) ، والطابع المستقل(karakter mandiri), والطابع القومي (karakter religius) تثغيلها معا في وحدة التدريس في مؤسسة تعليمية. ومع ذلك، فبان تعليم الثخصية الدينية هو في صميم القيم الخمس الرئيسية، قال Adian Husaini (2020 ) الطلاب ذوو الثخصية الدينية لا يفعلون الثر أو الظلم ، وبالنسبة له فإن الثناء مرض قلبي للطلاب الذين لديهــشخصية دينية. قال Muhammad Ali Ramdhani (2014 ) إن تعليم الثخصية يرتبط ارتباطاً وثيقاً ببيئة التعلم، لأنه يعتقد أن بيئة التعلم والتربية هي دورة من التأثير على بعضها البعض. يمكن خلق بيئة جيدة كتأثيـر من الطلاب الملتزمين بتنفيذ البرامج التعليمية ، بالاضضافة إلى أن الطلاب المؤهلين سيثكلون بيئة مواتية ويدعمون برامج التعلم. لذا فإن أحد مفاتيح التعليم، وخاصة تعليم الثخصية هو تهيئة بيئة جيدة حتى يمكن تحقيق الأهداف التعليمية. هذا يتماشى مع آراء Firdaus et al, ) (2010) Hakam و 2020) (modelling) (لثبية الثخصية سيكون فعالا عندما تدعمها نهج النمذجة (20) ، والتعود (habituating) ، والتدريب (tarining) وتكييف (conditioning) جيدة.

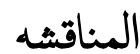

كان محمد ناصر (1908-1993) من بين سكان جهورية إندونيسيا الذين أولوا اهتماماً كبيراً dewan ( لمثكلة الدعوة والمسلمين. ويتجلى ذلك في إنثاء المجلس الأعلى للدعوة الإسلامية إندونيسيا (Bachtiar, الذي يركز على خدمة المسلمين من خلال حركة الدعوة (da'wah islamiyyah indonesia 2018; Hakiem, 2019; Humas DDII Pusat, 2020; Rabbanie et al., 2019).( قبل محمد ناصر والثخصيات المؤسسة للدولة الوحدوية لجمهورية إندونيسيا (NKRI) بما في ذلك H.M Prawoto Mangkusasmito، Buchari Tamam ، Rasjidi عمل محمد ناصر في بناء الثعب من خلال حركة الدعوة، بعد أن تم حظره وتقييده من تحركاته 
السياسية من قبل orde baru. وقد وضع محمد ناصر DDII باعتباره بيتًا كبيرًا للمسلمين ومكانًا للتداول حول القضايا المثيرة للاهتمام وتسهيل المساعدة المختلفة لمؤسسات الدكوة الأخرى رل (2019 من تجربته مع واقع المسلمين في ذلك الوقت ، بالاضافة إلى خبرته خلال الفترة الاستعمارية، وفترة الاستقلال ، وفترة النظاه القديم (orde lama) وفترة النظام الجديد) orde baru) ، خلص محمد ناصر إلى أن طباعة الجيل القاده من الدعوة هو صراع حتي لا مفر منه لدعم الدعوة لا يتوقف مع مرور زمان ، فقد صاغ أنه يجب أن يكون هناك تكامل بين المساجد (masjid) وبسنتران (pesantren) والجامعات (kampus) في عملية كوادرة مقاتلي الأمة (Rabbanie et al., 2019) وذكر Muhammd Sidik أن هذا المفهوم مثلي مع الوضع في إندونيسيا ، لأنه راسخ ومتجذر في الثقافة الإندونيسية، لذلك سيظل مفهوه التكامل هذا ذا صلة يتم في إندونيسيا ، لأنه يتفق مع قيم وأهداف الإسلاه و الثنافة الإندونيسية.(Dewan Dakwah Islamiyyah Indonesia, 2020) منهوم Triple Helix لمحمد ناصر ومن بين مساهمات محمد ناصر العظيمة في التعليم في إندونيسيا ثمرة تفكيره في دمج التعليم بين المساجد (masjid) وبسنتران (musaini \& Setiawan, والجامعات (kampus) (pesantren) فإن هذا المفهوه هو تفتيت لمحمد (Rabbanie et al., 2019) Syamsul Bahri Ismail قال 2020). ناصر الذي يعيث في عصور أربعة، وهي الحقبة الاستعمارية (1925-1945) ، وفترة الاستقلال (1945-

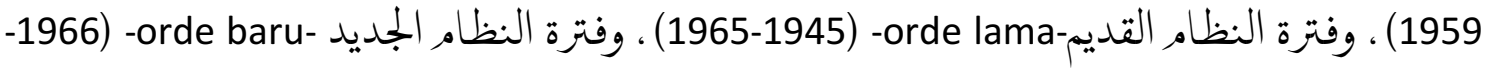
1993). يدرك محمد ناصر جيداً أن القوة المحتملة للمسلمين يمكن أن تنمو وتتطور في هذه

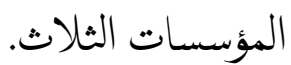


قال محمد صديق (Dewan Dakwah Islamiyyah Indonesia, 2020) ينبني الاستمرار في تعزيز تفكير محمد ناصر المدوي حول الركائز الثلاث لقوة المسلمين لأنه سيظل وثيق الصلة بالأجواء والظروف في إندونيسيا، لأنه بالاضافة إلى الثخصية التي أنجبت الفكرة هي إندونيسي، فإن المفهوه قد تأصل أيضاً في إندونيسيا، بحيث يتماشىفهوه triple helix مع مفهوه الإسلاه و وإندونيسيا الذي يثار إليه على نطاق واسع بمفهوم التنمية الإسلامية المثالية في إندونيسيا.

وستطلق حكومة إندونيسيا، من خلال وزارة التعليم والثقافة، سياسة جديدة في العملية

التعليمية، ويسىى هذا المفهوم -merdeka belajar, kampus merdeka-. وعلى الرغم من أن تنفيذ هذه السياسة قد تم تنفيذه من قبل مختلف المؤسسات التعليمية في إندونيسيا ، فإن هذه السياسة هي على الأقل إضفاء الطابع القانوني وتوسيع نطاق التكامل التعليمي الذي قامت به المؤسسات التعليمية، ولا سيما المؤسسات التعليمية المحلية (swasta). الغرض من هذا المفهوه هو أن عملية التعلم ليس دائما في الفصول الدراسية، بل يمكن أن تُعظم بأقصى قدر من خلال الدخول مباشرة في مجال الكفاءة الرئيسية حسب برنامج الدراسة (program studi) . على الرغم من أن الأنثطة خارج الصف قد تم القياه بة أيضا من خلال التدريب الداخلي (magang) ، والعمل الميداني المنزلية (PKL) ، وبرامج تعزيز الكفاءة (PPK) ، ومحاضرات العمل الحقيقي (KKN) وغيرها من الأثنطة ، ولكن لا يزال يعتبر الجزء من الوقت المسموح به الحد الأدنى. ومن خلال سياسة حرية التعلم (merdeka belajar) التي ستنفّذ في عام 2020، يمكن القيام بالأثطة خارج الفصول الدراسية إلى أقصى حد، ومنحها جزءاً أكبر من الوقت من النظاه السابق. 
9 Untuk meningkatkan hubungan dengan dunia kerja, mahasiswa didorong untuk belajar di luar program studi mereka selama 3 semester dari 8 semester pendidikan

Mahasiswa memiliki hak 3 semester untuk mendapatkan pengalaman di luar Prodinya:

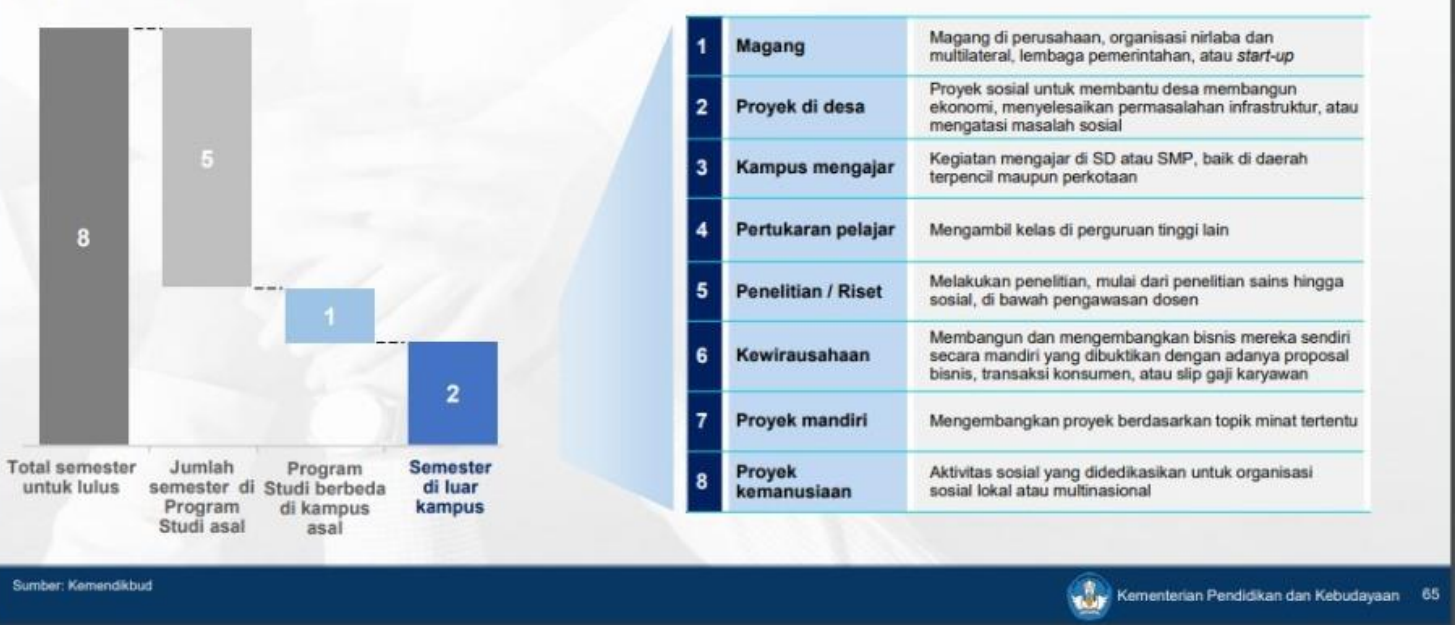

الثكل 1 . مفهور -merdeka belajar, kampus merdeka

$$
\text { المصدر: خارطة طريق التعليم الإندونيسي 2020-2035 ، وزارة التعليم والثقافة لعام } 2020
$$

(4) Hak mengambil mata kuliah di luar prodi dan perubahan definisi Satuan Kredit Semester (sks)

\begin{tabular}{l} 
Situasi saat ini \\
$\begin{array}{l}\text { Mahasiswa tidak memiliki } \\
\text { banyak fleksibilitas untuk } \\
\text { mengambil kelas di luar prodi } \\
\text { dan kampusnya sendiri }\end{array}$ \\
$\begin{array}{l}\text { Bobot sks untuk kegiatan } \\
\text { pembelajaran di luar kelas } \\
\text { sangat kecil dan tidak adil bagi } \\
\text { mahasiswa yang sudah } \\
\text { mengorbankan banyak waktu }\end{array}$ \\
$\begin{array}{l}\text { Di banyak kampus, pertukaran } \\
\text { pelajar atau praktik kerja justru } \\
\text { menunda kelulusan mahasiswa }\end{array}$ \\
\hline
\end{tabular}

\section{Arahan kebijakan baru}

Perguruan Tinggi wajib memberikan hak bagi mahasiswa untuk secara sukarela (dapat diambil

- Dapat mengambil sks di luar perguruan tinggi sebanyak 2 semester (setara dengan $\mathbf{4 0}$ sks)

- Ditambah lagi, dapat mengambil sks di prodi yang berbeda di PT yang sama sebanyak 1 semester (setara dengan 20 sks)

Dengan kata lain sks yang wajib diambil di prodi asal adalah sebanyak 5 semester dari total semester yang harus dijalankan (tidak berlaku untuk prodi Kesehatan')

Perubahan definisi sks:

- Setiap sks diartikan sebagai "jam kegiatan", bukan "jam belajar".

- Definisi "kegiatan": Belajar di kelas, praktik kerja (magang), pertukaran pelajar, proyek di desa, wirausaha, riset, studi independen, dan kegiatan mengajar di daerah terpencil. Semua jenis kegiatan terpilih harus dibimbing seorang dosen (dosen ditentukan oleh PT)

- Daftar "kegiatan" yang dapat diambil oleh mahasiswa (dalam 3 semester diatas) dapat dipilih dari: (a) program yang ditentukan pemerintah, (b) program yang disetujui oleh rektor

الثكل2 ـ مفهور -merdeka belajar, kampus merdeka

المصدر: خارطة طريق التعليم الإندونيسي 2020-2035 ، وزارة التعليم والثقافة لعاه 
فيما يتعلق بمفهوه triple helix محمد ناصر، يمكن لتربية الثخصية الدينية التي تم القيام به في الجامعات القيام بأساليب تعليمية الاجتهاد من خلال الاستفادة من سياسة دراسة مستقلة وحره جامعي مستقل-merdeka belajar, kampus merdeka- من خلال دمج التعليم في الحره الجامعي مع المساجد (masjid) وبسنتران (pesantren) ، كان ذلك داخل أو خارج الجامعة.

\section{1.التكامل بين الجامعة و المجد}

المسجد هو أقده مؤسسة في عملية نثر الإسلام، المؤسسة التي بناها محمد

(Malim \& Solihin, 2010; عندما هاجر من مكة المكرمة إلى المدينة المنورة هو بناء مسجد قباء Zubaidi, 2019) في هذا المسجد الأول، قاه النبي صلى الله عليه وسلم ببث مختلف البرامج الإسلامية، ووضع خطة الدعوة وتدريب الأمّة. المسجد له روابطه الخاصة بالإسلاه، لذلك فهو رمز للمسلمين. إن الكرامة والجوانب الدينية القيمة لمباني المساجد لها قيمتها التعليمية الخاصة. إن التاريخ الطويل لتطوير المساجد في إندونيسيا يعني أن وجود المساجد سيكون متيناً إلى جانب نمو المسلمين الذي ينمو من عام إلى آخر. لذلك، للمساجد معنى مهم في عملية تمكين المجتمع في إندونيسيا. ومن بين البرامج التي يمكن التكامل بين الجامعة و المسجد هو برنامج التدريب في المسجد، التي تثارك كمدير للمسجد، بحيث سيكون هناك الطلاب الذين لديهـــ نظرة كاملة على تمكين المجتمعات القائمة على يلى المساجد. بالاضافة إلى ذلك، ومن بين البرامج التي يمكن تنفيذها في المساجد التي تمتلك إمكانيات جيدة للقيام بمثاريع الدعوة والإنسانية القائمة على المساجد ، وذلك من خلال سياسة دراسة مستقلة وحره جامعي مستقل(merdeka belajar, kampus merdeka). ويمكن تنفيذ المشروع لسيمستر (semester) واحد على الأقل مع برامج مختلفة، بما في ذلك إدارة تدريب مجموعات المعلاف، وتدريب الثباب، ورسالة التخفيف من كثابة القرآن، وتخفيف العبادة الفتهية وخاصة في المناطق الحضرية، وغيرها من المشاريع ذات الصلة ببرنامج تربية الشخصية الدينية. هذا المشروع ينفذ لمدة فصل دراسي واحد ويمكن أن تعترف به الكلية كمساق محدد ذي صلة. بالطبع، لكي يتم تشغيل هذا 
المشروع بثكل صحيح، يجب أن يكون هناك تكامل جيد وتواصل بين المؤسسات والمساجد ، بحيث حتى لو كان الطلاب خارج الجامعة فإن عملية التعليم والتقييم لا تزال تخضع للمراقبة والاضطلاع بها بثنل دوري.

\section{2. التكامل بين الجامعة و وبسنتران (pesantren)}

بنتران (pesantren) هي مؤسسة ولدت من ثقافة السكان الأصليين في اندونيسيا ، على الرغم من أن جوهر بسنتران هو القيام بمهمة لتعميق الدين الذي تم القيامر به منذ المرة الأولىمن قبل النبي وأصحابه ، يتم تعديل بسنترانات في رحلتها إلى العادات الثقافية المحلية في إندونيسيا ، بحيث يكون لها خصائص اندونيسيا .(Sukamto, 1999)

قال عبد الرحمن وحيد (1988) بسنتران في تاريخه احتل موقعاً استراتيجياً في مختلف مناحي الحياة، واكتسب نفوذاً وتقديراً كبيرين تمكنا من التأثير في جميع مناحي حياة الناس ، وقوته أسطورية بسب شخصية كياي (kyai) والدعم الكبير سانتري (santri) المنتشر في المجتمع. وعلى غرار المساجد ، فإن بسنتران في إندونيسيا له تاريخه، لا سيما في العصور الاستعمارية، فبسنتران هو مركز مقاومة الغزاة، وذلك ضد الثقافة والمعتقدات التي يحملها المستعمرون (Sukamto, 1999)و قال Sukamto تنقسم فبسنتران في اندونيسيا إلى نوعين ، الأول فبسنتران التي تحتفظ بخصائصها الأصلية ، وتسىى بالفبسنتران التقليدي (pesantren tradisonal). ومن بين ميزاته عملية التدريس التي تركز على كياي (kyai) مع طريقة تدريس السوروغان (sorogan) والسيستين (bandongan) في الدراسة. ولا تزال هذه المجموعة تحتفظ بخصائص المدرسة الداخلية الاسلامية في الحقبة الاستعمارية التي أنثئت كمناد للثقافة والمعتقدات الجديدة التي جلبها الغزاة، بحيث تم تعميم جوانب من الجدة التي جلبها الغزاة على أنها خطيرة وسيئة. المجموعة الثانية فبسنتران الذي يتضمن عناصر من التعليم العام في برنامها التعليمي، بحيث لا يجصل الطلاب على التعليم الديني من كياي (kyai) فحسب. 
ولكن أيضا الحصول على رؤى عامة أخرى. ولكل من هذين النمين، التقليدي (tradisional) والحديث(modern) ، مزاياه وعيوبه. النموذج التقليدي سميك جدا مع الثقافة الإندونيسية، وخاصة ثقافة جاوة (jawa) ومادورا(madura) ، حيث هناك الطبقات الاجتماعية في حياة الناس. وهذا يعني أن مكانة كياي الرفيعة في المجتمع تجعله شخصية مورية في نشر المعرفة وتفتيح الخطاب في وسط المجتمع قوة نموذج المدرسة الداخلية الحداثية هي في استعدادها وقدرتها على الانخراط في اضطرابات العصر (Sukamto, 1999). يعتبر النموذج الحداثي خطوة أفضل، لأن الإسلاه يتأقلم في الواقع مع تطور العصر، ويمكن رؤية ذلك من حقيقة تاريخية مفادها أن الإسلاه الذي تطور في الشرق (Bachtiar, 2018; الأوسط كان ذات يوه مركز الحضارة العالمية. كما تم الكثف عن محمد ناصر أن المسلمين لا ينبني أن يكونوا معادين للحداثة والعلوه التي يجلبها الغرب ويطورها. ليس كل ما يأتي من الغرب سيء، ولا يأتي من الثرق كل الخير. بين العلوه الدينية والعلوه العامة ينبغي أن يكمل بعضها بعضا والتآزر، لا ينبني أن تكون شنائية أوثنائية.

أصبحت شخصية كياي (kyai) و بسنتران عنصراً مهماً في غرس قيم الدعوة والقيم الإسلامية

لطلاب العلم. وفقا ل Assiroji (2020) تربية الشخصية الطلاب (santri) هو جوهر التعليم في بسنتران، لأن المطلوب ليس فقط أن يتقن ولكن أيضا تستخدم في شكل مواقف يومية تصبح المؤشرات. إن التكامل بين الجامعة و وبسنتران (pesantren) مهم جداً، خاصة من أجل فهم الطلاب المحتملين حول الثقافة للمجتمع الاندونيسي. كما هو الحال مع نموذج التعلم المتكامل بين الجامعة والمسجد سابقا، يمكن أيضًا التكامل بين الجامعة و وبسنتران بهدف رئيسي هو تعزيز الطابع الديني للطلاب من خلال إضفاء الطابع الداخلي على القيم البسنترانية والقيم الإسلامية. وكما يقول Hakam (2010), فإن تعليم الثخصية المناسبة لمستوى الكلية هو نهج البناء الذي يؤكد على جوانب النمذجة والتكييف والتعود. في هذه المرحلة، يتعلم الطلاب معنى معين بثكل مستقل من خلال البحث، 
ورؤية، وتجربة القيم التي هي موجودة والتي قدمت قبل ذلك. يمكن أن يتم التكامل بين الجامعة و وبسنتران من أجل إجراء عملية تعلم دورات مجموعات المواقف والمهارات للطلاب.

تطبيق التكامل بين الجامعة ووبسنتران تطبيق التكامل بين الجامعة و أنواع الأنثطة المسجد

التدريب التدريب في مسجد بالمشاركة في يمكن أن يتم التدريب في بسنتران مع

ازدهار المسجد من خلال المشاركة في التدريب الكامل أو أخذ وقت الفراغ في جميع الأثشطة في المسجد بالتعليم الكلية. الأثطة التي يمكن القياء بها والأنثطة المجتمعية ومساعدة مصالح بالاضافة إلى اتباع دروس بسنتران وأن المسجد وفقا لمجال معارفه الخاصة تساعد مصالح مختلفة من بسنتران وفقا لمجال العلوه أو الدراسة. - ماس.

(program studi)

المشاركة في البرامج الإنسانية القائة بالاضضافة إلى اتباع دروس بسنتران يمكن المشاريح على المساجد التي تناسب معارفهم أو أيضا أن تثارك في تطوير المجتمع

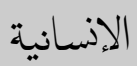
برامج الدراسة، على سبيل المثال القائم على بسنتران وفقا للكفاءة في يمكن للطلاب كلية الطب أداء برنامج الدراسة. الخدمات الاجتماعية في المساجد.

أن يكون مصدر الأنثطة العلمية التي وبالاضافة إلى حضور دروس بسنتران، تعليم يقوه بها بجلس ازدهار المسجد وفقًا يمكن للطلاب أن يصبحوا معلمين لمواد بسنتران وفقاً لكفاءاتهــ المعرفية. لكفاءة علومه. بكوث التنمية إجراء البحوث لدعم تطوير المساجد بالاضافة إلى حضور دروس بسنتران. 


$$
\begin{aligned}
& \text { المحتملة والبحث عن فعالية برامج يمكن للطلاب القياء بأبحاث لتطوير } \\
& \text { بسنتران والبحث عن فعالية برنامج } \\
& \text { المساجد. } \\
& \text { بسنتران. }
\end{aligned}
$$

الجدول 1. تطبيق -triple helix- محمد ناصر

إن التكامل بين الجامعة و المسجد و بسنتران هو طريقة مثلي تربية الثخصية الدينية.

المسجد و بسنتران هي من أقده المؤسسات الإسلامية في إندونيسيا ، لذلك لديها جذور التي ترتبط بالثقافة الإندونيسية. يجب الاستفادة من برنامج -merdeka belajar, kampus merdeka- على النحو الأمثل. بحيث يكون لخطة إن التكامل بين الجامعة و المسجد و بسنتران تأثير في في تربية الثخصية الدينية للطلاب. من بين البرامج التي يمكن تنفيذها في إن التكامل بين الجامعة و المسجد و بسنتران هي برامج التدريب المهني ، وعقد المشاريع الإنسانية المشتركة ، والتعليم ، وبكوث التطوير المؤسسي. لكي يعمل هذا المفهوه بثكل جيد، يجب أن يكون هناك تعاون قوي بين المؤسسات الثلاث في تحقيق الأهداف التعليمية ، وتكامل المناهج وتحويلها ، والمراقبة والتقييم أثناء البرنامج.

\section{REFERENCE}

Assiroji, D. B. (2020). Konsep Kaderisasi Ulama di Indonesia. Edukasi Islami: Jurnal Pendidikan Islam, 9(1). https://doi.org/DOI : 10.30868/ei.v9i01.661

Bachtiar, T. A. (2018). Jas Mewah, Jangan Sekali-kali Melupakan Sejarah dan Dakwah. Pro-U Media.

Dewan Dakwah Islamiyyah Indonesia. (2020). Simposium Nasional Tiga Pilar Dakwah (Masjid Pesantren Kampus). Dakho TV. https://www.youtube.com/watch?v=5zrfslM8g0c\&ab_channel=dakhotv 
Firdaus, R., Hakam, K. A., Somad, M. A., \& Rizal, A. S. (2020). Konsep Triple Helix Mohammad Natsir Relevansi Dan Implementasinya Dalam Pendidikan Da'i Di Indonesia. Raayah Al-Islam. https://doi.org/10.37274/rais.v4i02.334

Hakam, K. A. (2010). Model Pembelajaran Pendidikan Nilai (D. Danang (ed.); I). CV Yasindo Multi Aspek.

Hakiem, L. (2019). Biografi Mohammad Natsir, Kepribadian, Pemikiran dan Perjuangan (Artawijaya (ed.); Pertama). Pustaka Al-Kautsar.

Humas DDII Pusat. (2020). Mengapa Dewan Da'wah Didirikan. https://www.youtube.com/watch?v=rTp7_yvHdfY\&feature=youtu.be

Husaini, A. (2020). Pendidikan Islam Mewujudkan Generasi Gemilang Menuju Negara Adidaya 2045 (IV). YPI At-Taqwa Depok.

Husaini, A., \& Setiawan, B. G. (2020). Pemikiran dan Perjuangan M. Nastsir dan HAMKA Dalam Pendidikan. Gema Insani.

Malim, M., \& Solihin, A. (2010). Dinamika dan Strategi Da'wah (M. Sulthoni (ed.); 2nd ed.). Media Da'wah.

Natsir, M. (2015). Capita Selecta (5th ed.). LAZIS DEWAN DA'WAH.

Rabbanie, abu T., Qomaruddien;, T. R., Hadi Nur Ramadhan;, \& Jeje Zainuddin. (2019). Tiga Pilar Da'wah, Masjid, Pesantren, Kampus Konsepsi, sinergi dan Aksi. Dewan Da'wah islamiyah Indonesia.

Ramdhani, M. A. (2014). Lingkungan Pendidikan dalam Implementasi Pendidikan Karakter. Jurnal Pendidikan Universitas Garut, 8(4), 28-37. http://journal.uniga.ac.id/index.php/JP/article/download/69/70

Sukamto. (1999). Kepemimpinan Kiai Dalam Pesantren (I). LP3ES.

Zubaidi, M. N. (2019). Optimalisasi Tiga Pilar Dakwah (Masjid, Pesantren, Kampus). Dewan Da'wah islamiyah Indonesia. 